\title{
CONTAMINACIONES NARCÓTICAS: 2666 DE ROBERTO BOLAÑO*
}

\author{
NARCOTICS CONTAMINATIONS: 2666 BY ROBERTO BOLAÑO
}

\author{
Bernardo Rocco \\ Universidad de Chile. Santiago, Chile. \\ stereohead73@gmail.com
}

\begin{abstract}
Resumen: El presente artículo considera la especificidad del imaginario narco-literario en 2666 de Roberto Bolaño. Lo anterior radica en la mutua contaminación de tres elementos temáticos. Primero, la violencia, al establecer una continuidad histórica entre las masacres de la II Guerra Mundial y los feminicidios en la ciudad de Santa Teresa. Segundo, el fenómeno de la intoxicación considerado como iluminación profana, tanto con respecto a la experiencia narcótica como estética. Finalmente, el capitalismo de frontera que sustituye el capital por la acumulación de cadáveres.
\end{abstract}

Palabras clave: Narco-narrativa, literatura y violencia, 2666, capitalismo en la literatura.

\begin{abstract}
This article considers the specificity of narco-literary imagination in 2666 by Roberto Bolaño. This lies in the mutual contamination of three thematic elements. First, violence, establishing an historical continuity between the massacres of the Second World War and femicides in the city of Santa Teresa. Second, the phenomenon of intoxication considered as profane illumination, both in terms of narcotic and aesthetic experience. Finally, the border capitalism replacing capital by accumulating corpses.
\end{abstract}

Keywords: Narco-narrative, literature and violence, 2666, capitalism in literature.

Recibido: 02.10.2015. Aceptado: 07.05.2016.

* Investigación elaborada en el marco del Doctorado en Literatura, mención Literatura Chilena e Hispanoamericana de la Universidad de Chile y financiada por la Beca de Doctorado Nacional CONICYT 2012. 


\section{Introducción}

-1 Nelación con los imaginarios y sus modos de narración Hermann 1 Herlinghaus señala en su libro Renarración y descentramiento: mapas alternativos de la imaginación en América Latina (2004) que es necesario recuperar las matrices heterogéneas de ambas nociones con el propósito de estudiar los espacios de imaginación e identidad: “[...] desde los cuales un pensamiento periférico interfiere en la reflexividad moderna de manera cada vez más activa” (15). En otras palabras, Herlinghaus está apuntando a la impresionante capacidad alterna que los saberes narrativos latinoamericanos tienen con respecto a la historia ordenadora del discurso, lo cual permite ingresar también a los conflictos asimétricos donde se forma la imaginación como fenómeno social y se negocian las nuevas construcciones simbólicas (17-18).

A lo que Herlinghaus se refiere, anticipando el fenómeno de la narconarrativa, es al profundo poder reflexivo y heterodoxo que los imaginarios latinoamericanos proponen con respecto a la experiencia contemporánea, en oposición al discurso homogéneo y racionalista estadounidense o europeo. En 2666 (2012) de Roberto Bolaño, la particularidad del imaginario narco-narrativo, al dar cuenta del tema del narcotráfico y de sus consecuencias en el norte de México, reside en una representación literaria extrema sobre la existencia del sujeto moderno que se asienta en el fenómeno de la violencia, la intoxicación y el capitalismo ${ }^{1}$.

\section{El fenómeno de la violencia}

Un caso paradigmático de cómo el fenómeno de la violencia informa 2666 corresponde a las complejas relaciones entre diversos y distantes imaginarios históricos sobre la violencia. Al respecto, Walter Benjamin (1986) en "Surrealism: The last snapshot of the European intelligentsia" (1929)

${ }^{1}$ En el capítulo introductorio "From Walter Benjamin's early writings to the perils of global Modernity" (3-28) de Violence without guilt: Ethical narratives from the global South (2008), Hermann Herlinghaus conecta detalladamente estos distintos fenómenos presentes en la narco-narrativa latinoamericana. 
reflexiona sobre el potencial revolucionario de la tan buscada imagen surrealista que se abre a la iluminación profana manifestando: "[...] the world of universal and integral actualities [...] more concretely, of bodies" (192). De este modo, la novela de Bolaño, al diseccionar la historia universal de la violencia, no sólo expone los imaginarios tan buscados sobre la violencia actual, sino que a su vez establece una continuidad temporal entre los imaginarios históricos y los asesinatos en masas: la esfera concreta de los cuerpos. Es lo que Alexis Candia, en su artículo "Todos los males el mal. La 'estética de la aniquilación' en la narrativa de Roberto Bolaño” (2010), siguiendo los planteamientos teóricos de Aldo Pellegrini, denomina "estética de la aniquilación”. En otros términos, Candia hace uso del concepto de aniquilación con el fin de caracterizar, en la obra de Bolaño, el tema la violencia, la cual se presenta como un rasgo inherente a la historia contemporánea:

Cuando Bolaño aborda los asesinatos de judíos en la Segunda Guerra Mundial, los crímenes de la dictadura militar chilena o la historia de las mujeres asesinadas en Santa Teresa no está sino plasmando esa "Estética de la Aniquilación" que tiene que ver con poner en escena las múltiples formas de destruir totalmente al otro, estableciendo como el horror y la violencia son parte del engranaje que ha movido, en cierta medida, la historia occidental durante los últimos siglos (50).

En este sentido, surgen dos interrogantes con respecto al cuerpo y el crimen considerados como espacios de la pluralidad: ¿cuál es la intención narrativa de exponer el crimen de masas en desmedro del crimen individual o de la preeminencia del evento criminal paradigmático -aunque recurrente a lo largo de la historia- en comparación con el evento criminal excepcional y único representado a menudo por el género policial? ¿Por qué la narración de 2666 insiste en el desvanecimiento de las distinciones entre la guerra y el delito: el espacio de la masacre? Al respecto, la única excepción ${ }^{2}$ presente en la novela confirma paradójicamente la regla de la masacre, es decir, el homicidio cometido por Hans/Archimboldi en contra

${ }^{2}$ La excepción no considera "La parte de los crímenes" debido a que la serie de asesinatos individuales conforman también en su totalidad el espacio de la masacre. 
de Sammer/Zeller, hecho que es descubierto luego de que ambos confiesan sus respectivos crímenes.

"La parte de Archimboldi" relata, entre otras historias, el encuentro de Reiter/Archimboldi con Zeller/Sammer en un campo de prisioneros en las afueras de Ansbach. Es aquí donde Zeller/Sammer le confiesa su programa de exterminio improvisado en un campo de concentración en Polonia. La narración -enmarcada por sus recuerdos o el punto ciego de sus experiencias- se sumerge en la cotidianidad absurda del proceso burocrático de exterminio de judíos de nacionalidad griega. De este modo, Reiter/Archimboldi se entera de que los prisioneros, cuyo destino final era Auschwitz, habían arribado por equivocación al pueblo polaco. En medio de la inesperada situación y de la orden perentoria de deshacerse de los prisioneros, Zeller/Sammer se ve obligado a implementar un improvisado plan de exterminio que incluye también la participación de unos niños alcohólicos. Este aspecto resulta de extrema importancia pues revela la función que Sammer/Zeller desempeña en la masacre de judíos, es decir, entre quien dirige la operación y quienes la ejecutan en terreno. Precisamente es lo que le ayuda a justificar sus crímenes ante Reiter/Archimboldi e imputar a los otros su propia culpa:

Fui un administrador justo. Hice cosas buenas, guiado por mi carácter, y cosas malas, obligado por el azar de la guerra. Ahora, sin embargo, los niños borrachos polacos abren la boca y dicen que yo les arruiné su infancia [...] iEl alcohol les arruinó su infancia! iEl fútbol les arruinó su infancia! iEsas madres holgazanas y descriteriadas les arruinaron su infancia! No yo. Otro en mi lugar [...] hubiera matado con sus propias manos a todos los judíos. Yo no lo hice. No está en mi carácter (959).

Algunos días después de la confesión aparece su cadáver cerca de una tienda de campaña. El asesino es Reiter/Archimboldi. Una muerte por estrangulación -en ningún caso un crimen de guerra o una masacre- del cual como le confiesa a Ingeborg sentía a veces arrepentimiento. Incluso en una conversación posterior le señala que los estadounidenses en realidad buscaban peces gordos, es decir, criminales de guerra con cierto prestigio. La confesión lleva a Ingeborg a contarle también que a veces piensa cuando hacen el amor y él la coge del cuello que es un asesino de mujeres. Una confesión-profecía que se cumplirá hacia el final de la narración a través de su 
sobrino Klaus. En un encuentro que sostiene Reiter/Archimboldi con una adivina -quien le recomienda que se cambie de nombre luego que intuyera que había matado a un hombre- permitirá que la confesión-profecía de Ingeborg se materialice -transmigre temporal y espacialmente de Europa a América - bajo la forma de un dogma policial: el asesino siempre vuelve al lugar del crimen. A un nivel metafórico, la paradoja -la advertencia de la adivina- se cumple cuando Archimboldi decide volver -a petición de su hermana Lotte- a la escena del crimen con el objetivo de ayudar a su sobrino -su alter ego- acusado de crímenes contra mujeres en Santa Teresa.

En esta misma perspectiva cabe recalcar, en "La parte de Fate", el episodio donde se describe la visita a la cárcel de una periodista llamada Guadalupe quien debe entrevistarse con Klaus Haas. Mientras Guadalupe espera en compañía de Rosa y Fate, Haas hace su entrada a la sala de visitas cantando en alemán: "Soy un gigante perdido en medio de un bosque quemado. Pero alguien vendrá a rescatarme [...] Soy un gigante perdido en medio de un bosque calcinado. Mi destino, sin embargo, sólo lo conozco yo" (439). Esta escena que presagia el viaje a México de su alter ego Reiter/Archimboldi se volverá a repetir más adelante en "La parte de los crímenes". En su primera noche en la cárcel Haas amenaza a un prisionero que se queja de sus ruidos:

No te tapes la cabeza, le dijo en voz alta y bien timbrada, igual vas a morir [...] va a venir un gigante y el gigante te va a matar [...] Estás loco, pinche gringo, dijo el ranchero [...] Al poco rato, sin embargo, Haas dijo que escuchaba sus pasos. El gigante ya está en camino. Era un gigante ensangrentado de la cabeza a los pies y ya se había puesto en camino (603).

Con respecto a la primera cita, se puede señalar que la metáfora del "bosque quemado o calcinado" sincroniza espacialmente la violencia de la II Guerra Mundial y el asesinato de mujeres en Santa Teresa. En otras palabras, la imagen del "bosque quemado o calcinado" alude doblemente a la imagen de la "selva negra" alemana arrasada por la guerra como al desierto mexicano o "bosque quemado" arrasado por la violencia.

De esta forma, se hace evidente el nexo con el concepto de "banalidad del mal" de Hannah Arendt, es decir, de cómo el acto de una persona común y corriente puede desatar un evento masivo de extraordinaria mal- 
dad. En efecto, un ejemplo que calza perfectamente con esta descripción corresponde al del soldado alemán Sammer/Zeller. En su reportaje de 1961 del juicio a Adolf Eichmann para la revista The New Yorker, que luego dio origen al libro Eichmann in Jerusalem: A report on the banality of evil (1963), Arendt plantea la cuestión de si el mal es radical o simple irreflexión. A lo que Arendt se refiere con el concepto de irreflexión es la tendencia existente de obedecer órdenes y cumplir con la opinión de las masas sin una evaluación crítica -reflexiva- de las consecuencias de las acciones o inacciones. Si bien Arendt centra su reportaje en la captura, juicio y ejecución de Eichmann, también es muy crítica con la forma en que el juicio es llevado a cabo en Israel, es decir, de los fundamentos jurídicos esgrimidos con respecto al tipo de crimen sin precedentes cometido por los nazis. En este sentido, Arendt no está de acuerdo con el término de genocidio usado durante el juicio a Eichmann -si bien en este caso es aplicable hasta cierto punto- pues este concepto refiere un tipo de masacre que ya ha sucedido en múltiples momentos de la historia universal y que, por lo tanto, no da cuenta cabal de la singularidad y excepcionalidad del crimen cometido por los nazis en contra del pueblo judío. Para ella, un concepto que sí describe bien el tipo de crimen cometido por los nazis es el de "masacre administrativa” impuesto por el imperio británico durante la ocupación de India. Al respecto, Arendt afirma lo siguiente: "The phrase has the virtue of dispelling the prejudice that such monstrous acts can be committed only against a foreign nation or a different race [...] that the principle of selection is dependent only upon circumstantial factors" (citado por Baehr, 2000: 380). De este modo, lo que Arendt intenta subrayar con esta afirmación es que los crímenes cometidos por los nazis -aunque fuesen ejecutados en contra del pueblo judío- son primero que todo actos criminales en contra de la humanidad:

[...] upon which the valid proposals for an international tribunal rested, stood in flagrant contradiction to the law under which Eichmann was tried [...] so these modern, state-employed mass murderers must be prosecuted because they violated the order of mankind, and not because they killed millions of people. Nothing is more pernicious to an understanding of these new crimes, or stands more in the way of the emergence of an international penal code that could take care of them, than the common illusion that the crime of murder and the crime of genocide 
are essentially the same, and that the latter therefore is "no new crime properly speaking” (citado en Baehr, 2000: 369).

Aquí Arendt no sólo crítica el hecho que Eichmann haya sido enjuiciado bajo una ley de por sí contradictoria e ilegal, sino que también se equiparasen los crímenes de asesinato y genocidio con el nuevo tipo de crimen en contra de la humanidad que ella señala en la cita como correspondiente a un orden legal completamente diferente. En consecuencia, Arendt reconoce un nuevo tipo de crimen que viola el orden internacional, el cual no puede ser cuantificado, sino al contrario debe ser completamente cualificado por un nuevo procedimiento legal acorde con la categoría del nuevo crimen.

De esta manera, el argumento de Arendt se devela de vital importancia para comprender la consistente representación en 2666 de las "masacres administrativas" en desmedro del crimen individual. En este sentido, no es sorprendente que Arendt afirme en una carta a Mary McCarthy que la: "[...] extermination per se is more important than anti-semitism or racism" (citado en Baehr, 2000: 389). En otras palabras, en 2666, al develar la existencia de una continuidad histórica -aparentemente desapercibida-, se instaura relaciones narrativas de carácter paradigmáticas y trans-históricas entre la violencia de las masacres durante la II Guerra Mundial y los crímenes de mujeres en Santa Teresa.

\section{El fenómeno de la intoxicación}

El fenómeno de la intoxicación no sólo informa 2666 sino que también induce la reflexión sobre los procesos históricos, sociales, políticos y económicos envueltos en la guerra global contra las drogas. Al respecto, Benjamin (1986) en el ensayo "Surrealism: The last snapshot of the European intelligentsia” (1929) afirma, en su análisis del movimiento surrealista, que la experiencia de la intoxicación o de perderse en sí mismo es precisamente de: "[...] living experience that allowed these people [surrealists] to step outside the domain of intoxication" (179). Con esta afirmación está describiendo la reflexión posterior sobre la experiencia de intoxicación o iluminación profana: “[...] a materialistic, anthropological inspiration, to 
which hashish, opium, or wherever else can give an introductory lesson [...] a dangerous one" (179). Si bien Benjamin verifica algunos rasgos de la iluminación profana entre los miembros del surrealismo, también constata lo cerca que estuvieron de apoderarse de las energías de la intoxicación. Para él, una forma de acceder a la misteriosa realidad cotidiana es a través de la experiencia de la intoxicación, consistente de un doble proceso reflexivo dialéctico, es decir, como pensamiento investigativo e iluminación profana (190). En este sentido, la intoxicación ${ }^{3}$ permea la representación de la novela de Bolaño, por ejemplo, mediante la reflexión profana sobre el fenómeno de la guerra a las drogas. No obstante, ¿̇qué otras formas adoptan las energías de la intoxicación o cómo se manifiestan narrativamente?

Un ejemplo de cómo el fenómeno de la intoxicación permea la narración se puede encontrar en "La parte de los críticos". Aquí se describen las distintas circunstancias que conducen a los críticos europeos a interesarse en la obra de Archimboldi, en particular, la fuerza adictiva que impone su enigmática figura. Incluso la creciente adicción por su vida y obra motiva a los críticos a viajar a México con el propósito de traerlo de vuelta a Europa. No obstante, el propósito de la búsqueda reside tanto en la posibilidad que Archimboldi obtenga el Premio Nobel de Literatura como en la eventualidad de que los críticos puedan conseguir algún tipo de dividendo profesional con su fama. Es en este espíritu de búsqueda que el narrador describe el estado emocional del crítico francés Pelletier luego de haber descubierto la obra de Archimboldi:

Entonces Pelletier pudo recordar el día en que leyó por primera vez a Archimboldi y se vio a sí mismo, joven y pobre [...] Se vio, como queda dicho, a sí mismo, ascético e inclinado sobre sus diccionarios alemanes, iluminado por una débil bombilla, flaco y recalcitrante, como si todo él fuera voluntad hecha carne, huesos y músculos, nada de grasa, fanático y decidido a llegar a buen puerto, en fin, una imagen bastante normal de estudiante en la capital pero que obró en él como una droga, una droga que lo hizo llorar, una droga que abrió, como dijo un cursi poeta holan-

${ }^{3}$ Entendida, según Benjamin, como pensamiento eminentemente narcótico e investigativo. Del mismo modo que la lectura como proceso eminentemente telepático. En esta misma lógica, se puede plantear también que la representación es un proceso eminentemente mimético. 
dés del siglo XIX, las esclusas de la emoción y de algo que a primera vista parecía autoconmiseración pero que no lo era (¿qué era entonces?, ¿rabia?, probablemente), y que lo llevó a pensar y a repensar, pero no con palabras sino con imágenes dolientes, su período de aprendizaje juvenil (16-17).

La lectura atenta y obsesiva de gran parte de la obra de Archimboldi entendida a su vez como experiencia eminentemente narcótica-, así como el recuerdo de su vida en ese particular momento de su existencia o de iluminación profana sobre sus condiciones materiales de vida como estudiante en París hacen que la imagen sobre su existencia obre: "[...] en él como una droga, una droga que lo hizo llorar, una droga que abrió [...] las esclusas de la emoción [...] que lo llevó a pensar y a repensar [...] con imágenes dolientes, su período de aprendizaje juvenil" (17). En otras palabras, la experiencia vivida en esa buhardilla de París fuerza a Pelletier a dar un paso fuera del dominio de la intoxicación (Benjamin, 1986: 179) para reflexionar sobre esa etapa de su existencia que concluye precisamente en el momento en que una nueva se abre gracias a Archimboldi. En este sentido, se puede afirmar -ampliando aún más la discusión sobre la dialéctica de la intoxicación- que la fascinación que los críticos europeos profesan por la obra de Archimboldi funciona adictivamente como un mecanismo de proyección de sus deseos y frustraciones, es decir, como placebo text:

[...] any unwritten cultural script that, like a religious text, informs a group's beliefs and expectations about a given drug, animating the "drug effects" once the substance is taken. If by placebo effect one means an outcome produced no by a drug but by beliefs and expectations about a drug, then a placebo text becomes the cultural teaching, however subtle, that inform these beliefs and expectations (DeGrandpre, 2006: 120).

De este modo, la obra de Archimboldi se transforma en el motor alucinógeno que informa el imaginario literario de los críticos, configurándose en el transcurso de la búsqueda del escritor alemán en un espacio que también moldea sus expectativas académicas y personales, en particular mediante la canalización de sus deseos latentes. En este sentido, Herlinghaus, en Narco-epics: A global aesthetics of sobriety (2013), clarifica que la experiencia estética de la obra como experiencia narcótica: 
[...] does not have to be of a chemo-biological nature, such as nicotine, alcohol, or LSD. Books, and the images that they (are made to) produce of their creator [...] can figure among the most powerful drugs in modern times [...] Again, addiction does not have to be a primordial matter of ingesting harmful narcotic product. When a book comes to play a "narcoticizing" role, there is not uniqueness per se about this book, but rather an aura that is formed through complex yet concrete relationships, in which physiological realities play their unacknowledged part, even in the case of works that produce their effect through fame, or mythic appeal (182-183).

Hacia el final de la cita, Herlinghaus se refiere a la formación aurea de relaciones complejas como las que se puede encontrar en "La parte de Amalfitano". En una conversación entre Marco Antonio Guerra y Amalfitano surge el nombre del escritor favorito de Guerra: Georg Trakl. La alusión al poeta y farmacéutico austríaco -fallecido a comienzos de la I Guerra Mundial de una sobredosis de cocaína- gatilla una sucesión de imágenes en la mente de Amalfitano mientras dicta una clase de manera automática (289). Es precisamente esta forma automática -modo surrealista de expresión libre del subconsciente- lo que induce en Amalfitano el recuerdo de una farmacia en Barcelona que quedaba cerca de su casa. En este sentido, lo que Amalfitano recuerda es la discusión sobre literatura con un joven empleado -muy parecido a Trakl- quien siempre leía de noche cuando la farmacia estaba de turno: "Una noche Amalfitano le preguntó, por decir algo mientras el joven buscaba en la estantería, qué libros le gustaban y que libro era aquel que en ese momento estaba leyendo” (289). Aquí la farmacia en una transposición de imágenes dialécticas se transforma en la "imagen-espacio" metafórico de la biblioteca donde la droga-libro gatilla la reflexión sobre obras menores como La metamorfosis o Bartleby versus obras mayores como El proceso o Moby Dick. Esta discusión literaria lleva a Amalfitano a un estado de iluminación profana que involucra en forma indirecta la "puesta en abismo" de un tipo de obra mayor muy parecida a la representada por la novela 2666 :

Ya ni los farmacéuticos ilustrados se atreven con las grandes obras, imperfectas, torrenciales, las que abren camino en lo desconocido. Escogen los ejercicios perfectos de los grandes maestros [...] no quieren saber 
nada de los combates de verdad, en donde los grandes maestros luchan contra aquello, ese aquello que nos atemoriza a todos, ese aquello que acoquina y encacha, y hay sangre y heridas mortales y fetidez (289-290).

La triste conclusión a la cual arriba Amalfitano permite de forma solapada una doble reflexión tanto sobre la estructura de la novela como de su contenido, de ese aquello que atemoriza: los crímenes de mujeres en Santa Teresa.

\section{El fenómeno del capitalismo}

"La parte de Fate" de 2666 presenta de manera bastante certera el fenómeno capitalista. Fate, al enterarse de los crímenes de mujeres mientras cubre para un periódico de Nueva York un combate de boxeo realizado en Santa Teresa, le propone a su jefe escribir: "Un retrato del mundo industrial en el Tercer Mundo [...] un aide-mémoire de la situación actual de México, una panorámica de la frontera, un relato policial de primera magnitud, joder" (373). No obstante, su jefe rechaza la idea debido a que: "[...] no hay ningún puto hermano en esa historia” (374) que justifique la investigación periodística sobre los asesinatos en México. Al describir su reportaje como un retrato del mundo industrial en el Tercer Mundo, Fate sintetiza uno de los argumentos de 2666 apuntando a la imagen del capitalismo en el Tercer Mundo como un orden trastocado u opuesto al mundo industrial del Primer Mundo. En este sentido, la captura fotográfica del momento histórico prometida por Fate muestra que ese retrato del mundo industrial es el resultado de la colisión entre el Primer Mundo y el Tercer Mundo, lo cual genera en el caso de la ciudad fronteriza de Santa Teresa un Mundo Capitalista de Frontera. Al respecto, Sergio González Rodríguez se refiere a este espacio del capitalismo fronterizo como twilight zone en su libro Huesos en el desierto (2002), es decir como una dimensión desconocida (14). De este modo, surge la interrogante sobre lo que representa esta dimensión desconocida del Capitalismo de Frontera.

En relación con lo anterior, Mark Neocleous plantea en el libro The monstrous and the dead: Burke, Marx, Fascism (2005) que detrás de la 
metáfora sobre los vampiros ${ }^{4}$ que utiliza Karl Marx para describir el capitalismo de la época se esconde una profunda inquietud por la tendencia del capitalismo hacia una política económica de la muerte:

But although capital may be dead labour, capital is also a highly active social agent: "a capital-in process, creative capital, sucking its living soul out of labour." The trouble with dead labour is that under the rule of capital refuses to stay dead: like the vampire, it returns to thrive off and control the living. Capital thus appears as dead labour turned into a form of life which in turn destroys the workers. Capital in this sense is both dead (labour) and living (power) (50).

En el caso particular de 2666, la descripción del funcionamiento del capital se puede verificar mediante la presencia en la frontera norte de México de las fábricas o maquiladoras -trabajo muerto o de acumulación de capital- donde trabajan las mujeres -fuerza viva o de poder de producción- de Santa Teresa. En este sentido, el punto de inflexión que agudiza la tendencia hacia la muerte de la economía capitalista se encuentra en las horas laborales a las cuales están expuestas diariamente las trabajadoras que, como temía Marx: "By extending the working day, therefore, capitalist production [...] not only produces a deterioration of human labour-power by robbing it of its normal moral and physical conditions of development and activity, but also produces the premature exhaustion and death of this labour-power itself" (citado en Neocleous, 2005: 52). De este modo, en "La parte de los crímenes", la fuerza laboral femenina muere literalmente a manos del Capitalismo de Frontera, más precisamente, bajo ciertas circunstancias -flujo ilegal de personas, drogas y armas- que po-

${ }^{4} \mathrm{Si}$ se considera la noción general sobre los vampiros como parásitos que chupan la sangre de sus víctimas en beneficio propio causando daño o muerte, entonces no es sorprendente que Benjamin se refiera al capitalismo en su fragmento de ensayo "Capitalism as Religion" como un culto religioso sin dogma que en sí mismo: "[...] developed parasitically on Christianity in the West -not in Calvinism alone, but also, as must be shown, in the remaining orthodox Christian movements- in such a way that, in the end, its history is essentially the history of its parasites, of capitalism" (1986: 260). La intención de Benjamin no consiste tanto en rastrear los orígenes del capitalismo como en trazar la historia de los distintos parásitos que tienen su origen en el capitalismo. En otras palabras, en vez de establecer una genealogía de la historia del capitalismo, su intención es desarrollar una fenomenología de la historia parasitaria del capitalismo. 
sibilitan la ejecución de los crímenes de mujeres: ecología del mal. Es lo que retoma Angélica Tornero en el artículo "La parte de los crímenes': Un mundo accidental en 2666 de Roberto Bolaño" (2012), cuando se refiere a los crímenes como consecuencia del proceso de desintegración que lleva a cabo el capitalismo:

En "La parte de los crímenes", asistimos a la ceremonia macabra de la desintegración no sólo del sujeto, sino también del cuerpo, propiciada por la ambición de unos cuantos y la pasividad y resignación de otros muchos. En Santa Teresa encarna el espíritu de esta etapa del desarrollo capitalista, y la literatura de Bolaño lo capta artísticamente, no ya como polifonía, sino como desintegración (82-83).

No obstante, esto aún no explica narrativamente la lógica descriptiva de la sucesión de muertes: la masacre. $\mathrm{Al}$ respecto, Neocleous advierte en relación a la metáfora del vampiro usada por Marx la presencia de otra que alude a la muerte. Esta metáfora pertenece al Evangelio de Mateo donde se describe el momento en que Jesús le responde a un discípulo que le pide tiempo para enterrar a su padre: "Follow me, and leave the dead to bury their own dead" (8:22). La frase sugiere que enterrar a los muertos es una costumbre que debe dejarse a quienes están espiritualmente muertos. Es decir, el radicalismo de la frase parece estar situada en la ruptura con las costumbres de la época relacionadas con el entierro. Como afirma Neocleous, Marx adopta esta frase agregándole "laméntenlos" con el propósito de mostrar que: "[...] this new political movement [communism] should not be burdened with the past. Humanity must learn to part with its past" (2005: 56). La importancia de la discusión teórica de Neocleous radica menos en el uso que hace Marx del Evangelio de Mateo en el ámbito del desarrollo del capitalismo del siglo xix que en la verificación del desarrollo extremo del capitalismo del siglo xxi representado por 2666. Si bien los temores de Marx con respecto a las condiciones laborales que impone el capitalismo se realizan plenamente en la novela, aún queda por entender el significado narrativo de los asesinatos. En este sentido, ¿qué rol cumpliría el Evangelio de Mateo en la comprensión de los asesinatos? Haciendo uso de un criterio más amplio que el utilizado por Marx para referirse al sistema capitalista del siglo xix, el pasaje bíblico permite reconocer una alegoría sobre el abandono: una imagen sobre el verdadero sacrificio de dejar atrás 
el pasado -los que han muerto- con el objetivo de seguir el Evangelio de Jesús o la promesa de un futuro mejor: la tierra santa/Santa Teresa. De este modo, ¿sería posible interpretar los crímenes de mujeres como una contra-alegoría sobre el abandono o la indolencia? Y si es así, ¿̇el probable luto sanador de quienes sobreviven a la muerte permitiría la redención de la comunidad? Aunque es plausible tal aproximación parabólica sobre los crímenes de mujeres, en especial si se piensa en el sentimiento de inercia o apatía que produce la incesante descripción de hallazgo de cadáveres, la interpretación se inclina hacia una dirección más acotada. En otras palabras, si la novela representa el capitalismo como un proceso simbólico de acumulación de cuerpos (capital) necesario para la producción e intercambio de cadáveres (bienes) con el fin de obtener mujeres asesinadas (dividendos), se puede entender el significado narrativo de los asesinatos como una alegoría sobre el capitalismo global de la frontera: un imaginario donde el capitalismo es el mal.

\section{Conclusiones}

La originalidad del imaginario narco-literario en 2666 de Roberto Bolaño reside en una representación extrema sobre la existencia del sujeto moderno que se asienta en el fenómeno de la violencia, la intoxicación y el capitalismo. Por una parte, la singularidad del tema de la violencia consiste en representarla como una continuidad histórica, a partir del nexo establecido entre las masacres de la II Guerra Mundial y los feminicidios en la ciudad mexicana de Santa Teresa. Por otra, el fenómeno de la intoxicación establece, en 2666, otro tipo de relación, esta vez sensible, entre la experiencia narcótica y la estética: procesos que permiten llevar a cabo una iluminación profana. Finalmente, el capitalismo se da a conocer desde el espacio de la frontera y como un sistema mortífero.

En definitiva, lo que parece ser el punto de contacto entre estos tres elementos -la violencia, la intoxicación y el capitalismo- es la confrontación, en 2666, de la realidad latinoamericana con un imaginario relativo al Primer Mundo: la II Guerra Mundial, la experiencia surrealista europea y el imperialismo económico estadounidense. En otros términos, se atestigua una doble contaminación, primero, con la novela de Bolaño catalo- 
gada como narco-novela, pero donde el tema del narcotráfico constituye solamente un telón de fondo -casi invisible- con el fin de insistir en sus manifestaciones concretas. Segundo, se da a conocer, en 2666, una contrahistoria en la cual los grandes relatos del Primer Mundo se encuentran reactualizados en el ámbito del Tercer Mundo. En definitiva, una genealogía del mal donde el narcotráfico es solamente el medio de una iluminación profana: el linaje de la devastación.

\section{Referencias}

Arendt, H. (1963). Eichmann in Jerusalem: A report on the banality of evil. New York: Penguin.

Baehr, P. (ed.). (2000). The portable Hannah Arendt. New York: Penguin Books.

Benjamin, W. (1986). Reflections: Essays, aphorisms, autobiographical writings. New York: Schocken.

Bolaño, R. (2012). 2666. Barcelona: Anagrama.

Candia, A. (2010). Todos los males el mal. La 'estética de la aniquilación' en la narrativa de Roberto Bolaño. Revista Chilena de Literatura, 76, 43-70.

DeGrandpre, R. (2006). The cult of pharmacology: How America became the world's most troubled drug culture. Durham: Duke UP.

González Rodríguez, S. (2002). Huesos en el desierto. Barcelona: Anagrama.

Herlinghaus, H. (2004). Renarración y descentramiento: Mapas alternativos de la imaginación en América Latina. Madrid: Iberoamericana. . (2008). Violence without guilt: Ethical narratives from the global South. New York: Palgrave Macmillan. . (2013). Narco-epics: A global aesthetics of sobriety. New York: BloomsBury.

Neocleous, M. (2005). The monstrous and the dead: Burke, Marx, Fascism. Cardiff: Wales UP.

Tornero, A. (2012). 'La parte de los crímenes': Un mundo accidental en 2666 de Roberto Bolaño. Revista de Literatura Hispanoamericana, 64, 65-99. 